\title{
Phase constitution of the noble metal thin-film complex solid solution system Ag-Ir-Pd-Pt-Ru in dependence of elemental compositions and annealing temperatures
}

\author{
Bin Xiao ${ }^{1}$, Xiao Wang ${ }^{1}$, Alan Savan ${ }^{1}$, and Alfred Ludwig ${ }^{1,2}(\bowtie)$ \\ ${ }^{1}$ Materials Discovery and Interfaces, Institute for Materials, Ruhr University Bochum, 44780 Bochum, Germany \\ ${ }^{2}$ Zentrum für Grenzflächendominierte Höchstleistungswerkstoffe (ZGH), Ruhr University Bochum, 44780 Bochum, Germany
}

(C) The Author (s) 2021

Received: 8 January 2021 / Revised: 8 April 2021 / Accepted: 12 April 2021

\begin{abstract}
Multiple-principal element alloys hold great promise for multifunctional material discovery (e.g., for novel electrocatalysts based on complex solid solutions) in a virtually unlimited compositional space. Here, the phase constitution of the noble metal system $\mathrm{Ag}-\mathrm{Ir}-\mathrm{Pd}-\mathrm{Pt}-\mathrm{Ru}$ was investigated over a large compositional range in the quinary composition space and for different annealing temperatures from 600 to $900{ }^{\circ} \mathrm{C}$ using thin-film materials libraries. Composition-dependent X-ray diffraction mapping of the asdeposited thin-film materials library indicates different phases being present across the composition space (face-centered cubic (fcc), hexagonal close packed (hcp) and mixed fcc + hcp), which are strongly dependent on the Ru content. In general, low Ru contents promote the fcc phase, whereas high Ru contents favor the formation of an hcp solid-solution phase. Furthermore, a temperature-induced phase transformation study was carried out for a selected measurement area of fcc- $\mathrm{Ag}_{5} \mathrm{Ir}_{8} \mathrm{Pd}_{56} \mathrm{Pt}_{8} \mathrm{Ru}_{23}$. With increasing temperature, the initial fcc phase transforms to an intermediate $\mathrm{C} 14$-type Laves phase at $360{ }^{\circ} \mathrm{C}$, and then to hcp when the temperature reaches $510{ }^{\circ} \mathrm{C}$. The formation and disappearance of the hexagonal Laves phase, which covers a wide temperature range, plays a crucial role of bridging the fcc to hcp phase transition. The obtained composition, phase and temperature data are transformed into phase maps which could be used to guide theoretical studies and lay a basis for tuning the functional properties of these materials.
\end{abstract}

\section{KEYWORDS}

noble metal high-entropy alloys, phase transformation, combinatorial synthesis and high-throughput characterization

\section{Introduction}

Multiple-principal element alloys (MPEAs), also known as highentropy alloys (HEAs) or compositionally complex alloys and solid solutions (CSS), have been the subject of extensive research and development since they were reported in 2004 [1]. Different from conventional alloy design concepts, MPEAs are not composed of only one or two major elements but contain five or more principal elements in a near-equal atomic composition with no obvious difference between the solute and solvent [2]. Several key properties are associated with these alloys: High lattice distortions related to atomic-size differences enhance the formation of random solid-solution phases, such as face-centered cubic (fcc), body-centered cubic (bcc) or hexagonal close packed (hcp) $[3,4]$. Moreover, due to the compositional complexity and chemical flexibility, the properties of MPEAs can be tuned, which provides a versatile platform to explore and study alloys with multifunctional properties [5-7].

Early-studied MPEAs were mostly composed of $\mathrm{Al}, \mathrm{Co}, \mathrm{Cr}, \mathrm{Cu}$, $\mathrm{Fe}, \mathrm{Mn}, \mathrm{Ni}$ and $\mathrm{Ti}$ as well as other transition metals [8-10]. Currently, 3d transition metal based alloying elements with possible additions of $\mathrm{Al}$ are the most reported MPEAs in Refs. [11, 12]. These MPEAs, which frequently form an fcc crystal structure, demonstrate exceptional physical and mechanical properties. The equiatomic transition metal system CrMnFeCoNi (Cantor alloy), as one of the first extensively investigated MPEAs, displays an exceptional combination of strength, ductility and fracture toughness at room temperature, all of which are further enhanced at cryogenic temperatures. From 2010 onwards, new refractory MPEAs have been explored, of interest for applications at ultrahigh-temperatures and harsh environmental conditions $[13,14]$. Most refractory MPEAs have $\mathrm{Zr}, \mathrm{Hf}, \mathrm{Nb}, \mathrm{Ta}, \mathrm{W}$ and $\mathrm{V}$ as their constituents and they tend to crystallize in bcc structure [15].

To date, owing to the advances in synthetic methodologies for exploring multifunctional materials, the study of MPEAs has undergone rapid expansion with numerous new members being developed, such as low density MPEAs [16], lanthanide MPEAs $[17,18]$ and noble metal MPEAs [19-21]. Recently, a series of mainly noble metal alloys chosen from Pd-Pt-Rh-Ir-Au-Ag-Cu-Ni have been reported to encompass a combination of high strength and high ductility. As an outstanding example among them, the equiatomic alloy PdPtRhIrCuNi has a compressive yield strength of $527 \mathrm{MPa}$, ultimate strength of $1,839 \mathrm{MPa}$, and strain to failure of $32.4 \%$. This senary alloy is synthesized by arc melting and forms in a fcc single phase with a completely dendritic microstructure. Beyond impressive physical and mechanical properties, noble metal MPEAs have also shown improved electrocatalytic activity 
compared to their "traditional" binary or unary subsystems. For example, hcp-IrOsReRhRu shows extraordinary catalytic activity in methanol electro-oxidation [22]. Besides, it is a unique highlystable MPEA that could stand extreme high-temperature (up to $1,500 \mathrm{~K}$ ) and high-pressure (up to $45 \mathrm{GPa}$ ) without phase transition. Another example is the recently reported equiatomic fcc-AgAuCuPdPt alloy which shows enhanced catalytic performance for $\mathrm{CO}_{2}$ reduction reaction [23]. However, compared to the reports published from transition and refractory metal MPEAs, not much is known about the phase stability and structural formation of their noble metal counterparts. Despite being very promising, the study of noble metal MPEAs is still at the infancy stage and requires further understanding in both experimental and theoretical aspects for accelerated materials discovery.

From the material synthesis side, traditional materials discovery has historically been carried out by one-at-a-time synthesis processes and serendipity. However, such a trial-and-error approach needs substantial time and laboratory work to explore the intrinsically complex alloys from a virtually unlimited compositional space [24-26]. Since the first combinatorial experiment performed in the 1950's, the "multiple-sample concept" (i.e., materials library) has made notable progress overcoming this barrier and speeding up the material discovery cycle [27-33]. By altering process and reaction conditions, the total number of experimental samples that can be screened exponentially, which drastically increases the chances of identifying a new material [34-38]. In particular, the thin-film based combinatorial approach, which allows substantially reduced costs and quantities of the raw materials used during synthesis, is of particular interest in the case of noble metal MPEAs, where a high success rate and cost-effectiveness would be highly desired in order to decrease the time and expenditure associated with this research. Once the thin-film samples are fabricated using combinatorial methods, high-throughput characterization approaches, which deal with a large number of samples, are required to efficiently determine the material structure and properties.

In this work, the system Ag-Ir-Pd-Pt-Ru was chosen, as recent data-guided experiments have indicated pronounced electrocatalytic activity for this system [39]. Presented herein is an in-depth study on the phase constitution of this system. By means of combinatorial co-sputtering from 5 confocal elemental targets, a quinary materials library (ML) was fabricated, spanning a large compositional range of $\mathrm{Ag}_{2-14} \mathrm{Ir}_{6-14} \mathrm{Pd}_{25-64} \mathrm{Pt}_{2-10} \mathrm{Ru}_{18-57}$. This composition range was chosen based on the observation of its catalytic behavior reported in a previous study [39]. Combinatorial thin-film fabrication allows engineering of alloy films within an extensive and controllable composition space, including many MPEAs deviating from near-equiatomic ratios. The as-deposited ML contains 342 measurement areas (MAs) with near-linear compositional gradients. As all MAs in a ML experience identical experimental treatments, errors related to sample-to-sample processing variations are eliminated, thus enabling systematic investigations of correlations among compositional information, phase formation and material properties. Due to the high-cost of noble metals, the film thickness of $100 \mathrm{~nm}$ was chosen, which was thick enough to ensure a continuous nanoscale thin film with sufficient material for the characterization and property measurements that were used. A series of high-throughput characterizations including energy dispersive X-ray spectroscopy (EDS), X-ray photoelectron spectroscopy (XPS) and X-ray diffraction (XRD) were applied for the screening of the MLs to explore correlations between composition and phase constitution. Our aim is to explore and understand the extent of different phases over the large composition space of the Ag-Ir-Pd-Pt-Ru ML in different processing states (as deposited, annealed), which is also of high importance for their functional, particularly electrocatalytic, properties. Furthermore, the obtained composition and temperature parameters are transformed into phase maps which could be used to guide theoretical studies and lay a basis for tuning the functional properties of these materials.

\section{Materials and methods}

\subsection{Combinatorial synthesis of Ag-Ir-Pd-Pt-Ru materials library}

A quinary Ag-Ir-Pd-Pt-Ru ML with a film thicknesses of around $100 \mathrm{~nm}$ was fabricated using a combinatorial magnetron sputtering system (DCA Instruments, Finland) by co-deposition from 5 confocal elemental targets, leading to well-defined compositional gradients. High-purity (Ag: 99.99\%, Ir: 99.9\%, Pd: 99.99\%, Pt: 99.99\%, Ru: 99.95\%) 100-mm-diameter Ag, Ir, Pd, Pt and $\mathrm{Ru}$ targets were used. Each target was positioned with an inclination angle of around $45^{\circ}$ with respect to the substrate, as indicated in Fig. 1(a). The elements and the corresponding cathode locations related to the ML are shown in Fig. 1(b). The deposition was carried out without intentional heating. A 100-mmdiameter sapphire wafer (c-plane) was used as substrate. It was patterned with small numbered crosses by a photolithographic liftoff process. Each patterned number was assigned to a MA, defined in a grid area with a size of $4.5 \mathrm{~mm} \times 4.5 \mathrm{~mm}$. Figure 1 (c) shows the coordinates and numbers for all 342 MAs in a ML. Prior to the deposition, the chamber vacuum was on the order of $10^{-5} \mathrm{~Pa}$. (a)

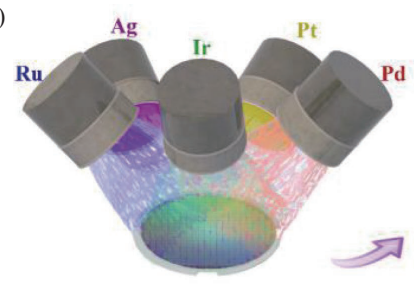

(b)

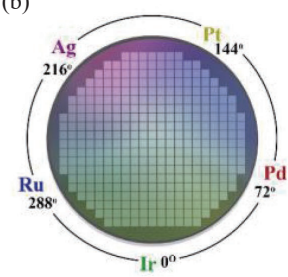

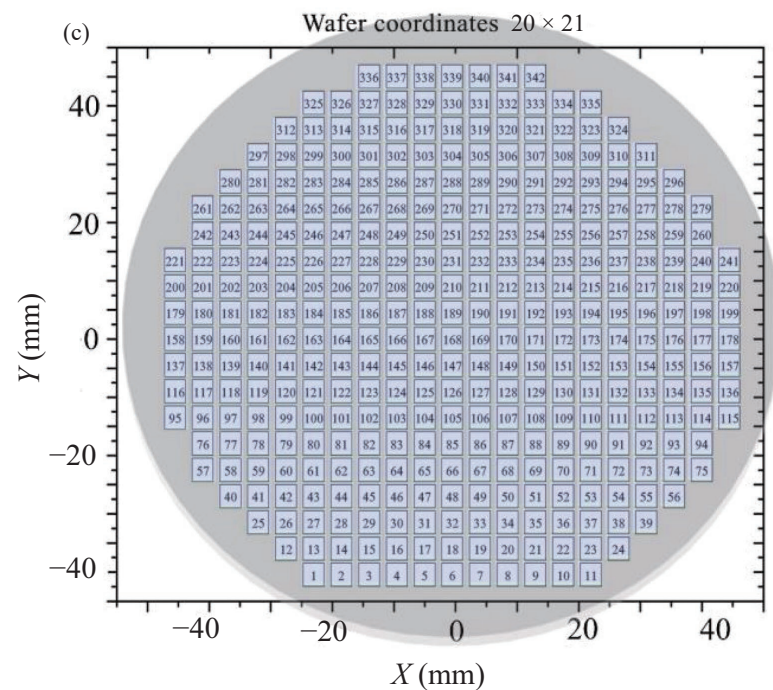

Figure 1 Schematic visualization of the combinatorial co-sputter process for the synthesis of a quinary composition spread thin-film ML. (a) Illustration of the 5 confocal magnetron sputter cathodes used for the fabrication of Ag-Ir-PdPt-Ru MLs. (b) View of the elements and the corresponding cathode locations related to a ML. (c) Coordinates and locations of the 342 MAs in a ML. 
During deposition, the pressure was set to $0.667 \mathrm{~Pa}$, and the substrate was kept stationary to obtain five continuous compositional gradients. The type of power supply used for each target and sputter powers are listed in Table 1. After deposition, the photoresist was removed in an ultrasonic bath.

Table 1 Sputter parameters for the Ag, Ir, Pd, Pt and Ru targets, respectively

\begin{tabular}{cccc}
\hline Target & Power type & $\begin{array}{c}\text { Deposition } \\
\text { power (W) }\end{array}$ & $\begin{array}{c}\text { Center composition } \\
\text { in ML (at.\%) }\end{array}$ \\
\hline $\mathrm{Ag}$ & Radio frequency & 57 & 10 \\
$\mathrm{Ir}$ & Radio frequency & 32 & 9 \\
$\mathrm{Pd}$ & Radio frequency & 174 & 41 \\
$\mathrm{Pt}$ & Radio frequency & 96 & 5 \\
$\mathrm{Ru}$ & Direct current & 133 & 35 \\
\hline
\end{tabular}

To investigate the phase constitution at high temperature, annealing experiments were performed at a series of temperatures ranging from 600 to $1,000{ }^{\circ} \mathrm{C}$ with temperature steps of $100{ }^{\circ} \mathrm{C}$ under high vacuum $\left(1.3 \times 10^{-5} \mathrm{~Pa}\right)$. Additionally, a MA with composition of $\mathrm{Ag}_{5} \mathrm{Ir}_{8} \mathrm{Pd}_{56} \mathrm{Pt}_{8} \mathrm{Ru}_{23}$ was separately annealed at several temperatures $\left(500,700\right.$, and $700{ }^{\circ} \mathrm{C}$, each for $10 \mathrm{~h}$ ) to further study its high-temperature phase transition behavior. For both annealing treatments, the heating rate during each annealing experiment was $50^{\circ} \mathrm{C} / \mathrm{min}$. After annealing, the system was cooled down naturally to room-temperature.

\subsection{High-throughput characterization of the materials library}

Compositions and phase constitution for all 342 MAs in the asdeposited Ag-Ir-Pd-Pt-Ru ML were investigated using automated, high-throughput characterization techniques. The elemental compositions were determined using automated EDX conducted on a JEOL 5800 scanning electron microscope (SEM). $20 \mathrm{kV}$ accelerating voltage, spot sizes of $50 \mathrm{~mm}$ and $10-\mathrm{mm}$ working distances with acquisition time of $60 \mathrm{~s}$ for each MA were used during the measurement. The excited X-ray energy lines for constituent elements are: Ag L $\alpha(2.984 \mathrm{keV}), \operatorname{Ir} \mathrm{L} \alpha(9.174 \mathrm{keV}), \mathrm{Pd}$ $\mathrm{L} \alpha$ (2.838 keV), Pt L $\alpha$ (9.441 keV), and $\mathrm{Ru} \mathrm{K} \alpha(19.233 \mathrm{keV})$. The analysis of EDX data was performed based on the standard ZAF correction process provided by the INCA Energy software (Oxford Instruments). The software was calibrated for quantification using pre-measured Co standard. After the hightemperature annealing experiment, the decomposition products were studied by XPS. A high-resolution X-ray photoelectron spectrometer (Kratos Axis Nova) equipped with monochromatic $\mathrm{Al} \mathrm{K} \alpha$ radiation $(1,486.6 \mathrm{eV} / 300 \mathrm{~W})$ was used as excitation source. The quantification of the chemical composition was done using standard sensitivity factors. The background was subtracted using the Shirley method. Film thickness was measured using a profilometer (Ambios XP2). High-throughput phase analysis was done using XRD (Bruker D8 Discover, equipped with a VANTEC500 area detector, $\mathrm{Cu} \mathrm{K} \alpha$ radiation, with a sample to detector distance of $149 \mathrm{~mm}$ ). The X-ray beam size was collimated to 1 $\mathrm{mm}$ in our experiment (collimator diameter $=1 \mathrm{~mm}$ with a divergence of below $0.007^{\circ}$ ). An area detector was used to collect the diffraction data, and 3 frames were collected for each measured area. These 3 frames were integrated into onedimensional data sets by using DIFFRAC.EVA software provided by Bruker and were then used for phase identification. The phases were identified by comparing the measured patterns with references from the Inorganic Crystal Structure Database (ICSD).

\section{Results and discussion}

\subsection{Composition-structure relations in as-deposited thin- film materials library}

The as-deposited ML has a center composition of $\mathrm{Ag}_{10} \mathrm{Ir}_{9} \mathrm{Pd}_{41} \mathrm{Pt}_{5} \mathrm{Ru}_{35}$. Figure 2(a) shows the compositional regions in color-coded scatter diagrams for each elemental constituent in this ML. Across the $342 \mathrm{MAs}$, the Ag content ranges from 2 at.\% to 14 at.\%, Ir from 6 at.\% to 14 at.\%, Pd from 25 at.\% to 64 at.\%, Pt from 2 at.\% to 10 at.\%, and Ru from 18 at.\% to 57 at.\%. The accuracy (about 1 at.\% experimental error) of this quantitative composition analysis is not affected by the substrate, because the substrate elements ( $\mathrm{Al}$ and $\mathrm{O}$ ) have different $\mathrm{X}$-ray emission peaks from those of the films. Based on this, the complete composition range of the ML is written as $\mathrm{Ag}_{2-14} \mathrm{Ir}_{6-14} \mathrm{Pd}_{25-64} \mathrm{Pt}_{2-10} \mathrm{Ru}_{18-57}$. This ML covers a large compositional space and it is rich in $\mathrm{Pd}$ and $\mathrm{Ru}$ and low in $\mathrm{Ag}$ and $\mathrm{Pt}$ content. To better visualize the relative elemental proportions across the ML, a pie chart diagram for all 342 MAs is plotted in Fig. 2(b). In each pie chart, the arc length of a slice is proportional to the element content it represents. A film thickness map for all 342 MAs is shown in Fig. S1 in the Electronic Supplementary Material (ESM). The thickness values range from 97 to $113 \mathrm{~nm}$ (mean value of around $100 \mathrm{~nm}$ ).

The phase diagrams of noble metals like Ag, Ir, Pd, Pt, and Ru normally indicate a simple fcc or hcp structure. However, their crystal structures can be modulated when their size shrinks to the nanometer scale or by changing the external conditions like pressure [40]. For instance, fcc to face-centered tetragonal (fct) transformation has been observed for Pd nanocubes under high pressure of $24.8 \mathrm{GPa}$ [41]. Recently, studies have also reported the selective control of fcc and hcp crystal structures in Au-Ru nanoparticles [42]. Below we will discuss the temperaturecomposition phase diagrams of the quinary Ag-Ir-Pd-Pt-Ru system.

The XRD patterns for all 342 MAs in the as-deposited Ag-Ir-Pd$\mathrm{Pt}-\mathrm{Ru} \mathrm{ML}$ are displayed in Fig. 3(a). The diffraction peaks in the $2 \theta$ range from $38^{\circ}$ to $53^{\circ}$ are characterized by Bragg reflections from fcc and hcp phases. Based on the comparison between experimental diffraction peaks with those of references from ICSD database, a phase map is obtained, as shown in Fig. 3(a). Clear phase boundaries are observed across the ML: 1) pure hcp phase on right side of the ML, 2) mixed hcp + fcc phases in the middle, and 3) pure fcc phase on the left side.

The large amount of data in Fig.3(a) makes it hard to distinguish finer details. Therefore, three MAs (\#57, \#241 and \#288) representative of their respective phase region are selected and enlarged in Fig. 3(b). Among them, \#57 and \#241 match well with pure hcp (ICSD-650586), and pure fcc (ICSD-198092), respectively, while \#288 is composed of both hcp (ICSD-640945) and fcc (ICSD-40348). For \#57 (hcp), the most intense reflection of $(002)$ is found at $40.2^{\circ}$, i.e. the preferred orientation is along the (002) plane. This peak is located between the other two intense reflections of (100) and (101), which are located at $38.3^{\circ}$ and $43.8^{\circ}$, respectively. In the case of \#241 ( $\mathrm{fcc}$ ), the diffraction patterns exhibit the highest intensity reflection along the (111) plane and four weak reflections along the (200), (220), (311) and (222) planes at $40.6^{\circ}, 47.1^{\circ}, 68.9^{\circ}, 80.4^{\circ}$ and $87.9^{\circ}$, respectively. Again, the observation of the most intense reflection along (111) for fcc phase indicates a preferential crystal orientation along this plane. Based on the XRD analyses, we conclude that the as-deposited ML is crystalline and comprises phase regions of (I) pure hcp, (II) pure fcc, and (III) mixed hcp + fcc. No other peaks which could indicate secondary phases or superstructures are observed in the ML. 

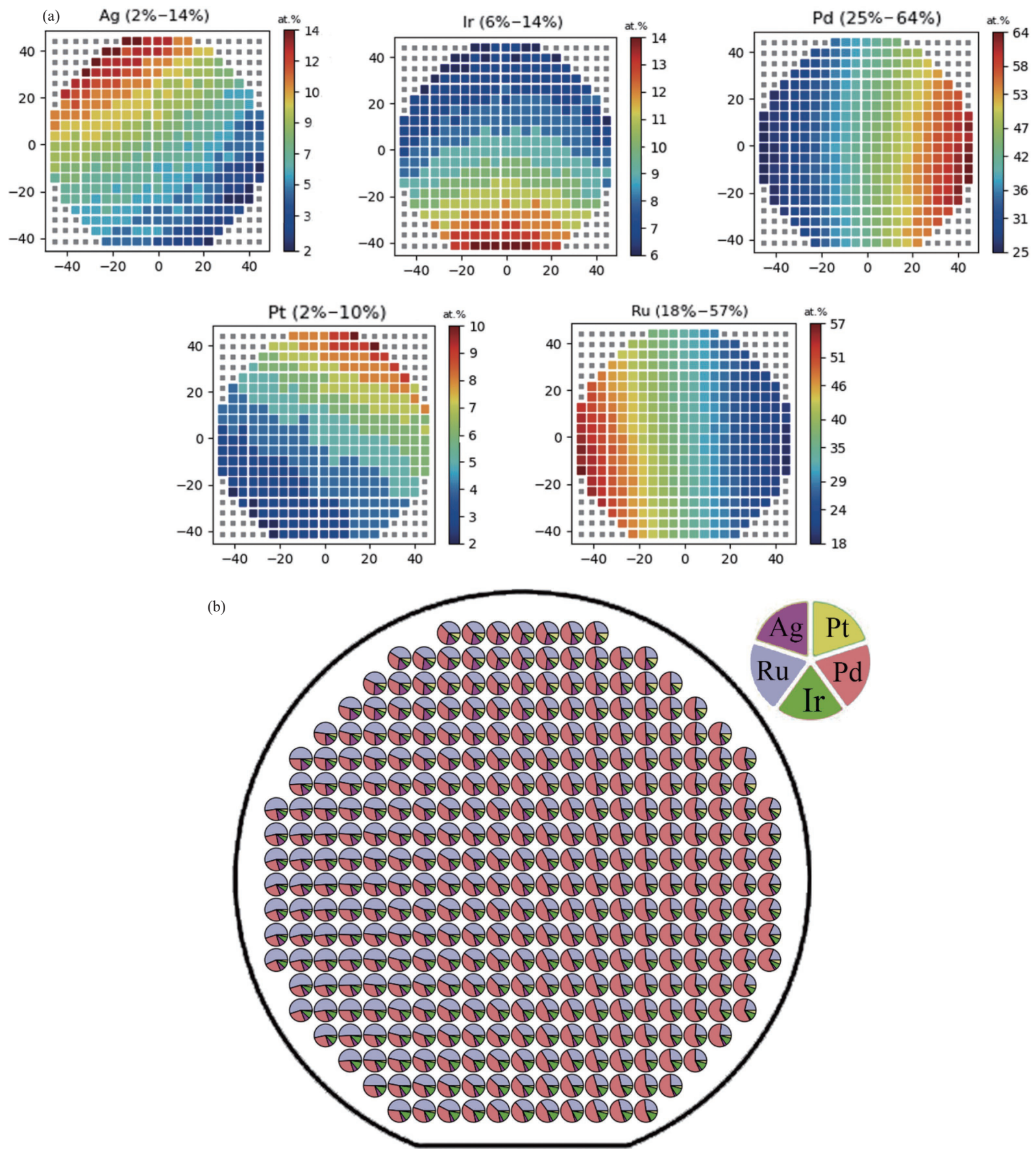

Figure 2 Composition space visualization of as-deposited Ag-Ir-Pd-Pt-Ru ML. The composition spread is $\mathrm{Ag}_{2-14} \mathrm{Ir}_{6-14} \mathrm{Pd}_{25-64} \mathrm{Pt}_{2-10} \mathrm{Ru}_{18-57}$ and the center composition is $\mathrm{Ag}_{10} \mathrm{Ir}_{9} \mathrm{Pd}_{41} \mathrm{Pt}_{5} \mathrm{Ru}_{35}$. (a) Color-coded diagrams show the element content for $\mathrm{Ag}$, Ir, $\mathrm{Pd}, \mathrm{Pt}$, and Ru, respectively. (b) Pie-chart diagram indicates the relative elemental compositions at each of the 342 MAs. The legend shows the locations of the elemental sputter sources with respect to the substrate.

Table 2 lists the structural information for Ag, Ir, Pd, Pt and Ru. These elements are $\mathrm{fcc}$ at room temperature, except for Ru which crystallizes in the hcp phase. This suggests that Ru content in the multinary film is decisive for phase formation of either fcc or hcp. In order to verify this hypothesis and study the correlation between $\mathrm{Ru}$ content in the quinary system and the associated phase boundaries, all 342 XRD patterns are plotted according to their $\mathrm{Ru}$ content: Figure 3(c) shows that Ru contents between 18 at.\% and 25 at.\% promote the generation of fcc phase, whereas higher $\mathrm{Ru}$ contents between 37 at.\% and 57 at.\% favor the formation of hcp solid-solution phase. In the intermediate composition range with Ru contents of 25 at.\%-37 at.\%, the films consist of a mixture of hcp and fcc phases.

Due to the large size of data and limited space, we selected three different compositions along the gradient containing a series of
MAs across the ML: (a) from bottom left to top right, (b) from left to right, and (c) from top left to bottom right (see Fig. 4). This selection is based on the general aspects of observed XRD patterns and positions of the sputter targets. Besides, the selected MAs along these three lines capture the representative characteristics in sufficient composition ranges. From Fig. 4, the phase evolution trend (hcp $\rightarrow \mathrm{hcp}+\mathrm{fcc} \rightarrow \mathrm{fcc}$ ) associated with the corresponding diffraction peak shifts and splitting can be seen in detail. Moreover, with the linear decrease in Ru content, that is, from left to right side of the ML, the intensities of hcp diffraction peaks reduce while fcc diffraction peaks increase.

\subsection{Temperature-dependent phase transformation}

Additional to the composition-dependent phase transition, the effect of annealing temperature ( $\left.T_{\text {anneal }}\right)$ on the phase constitution 

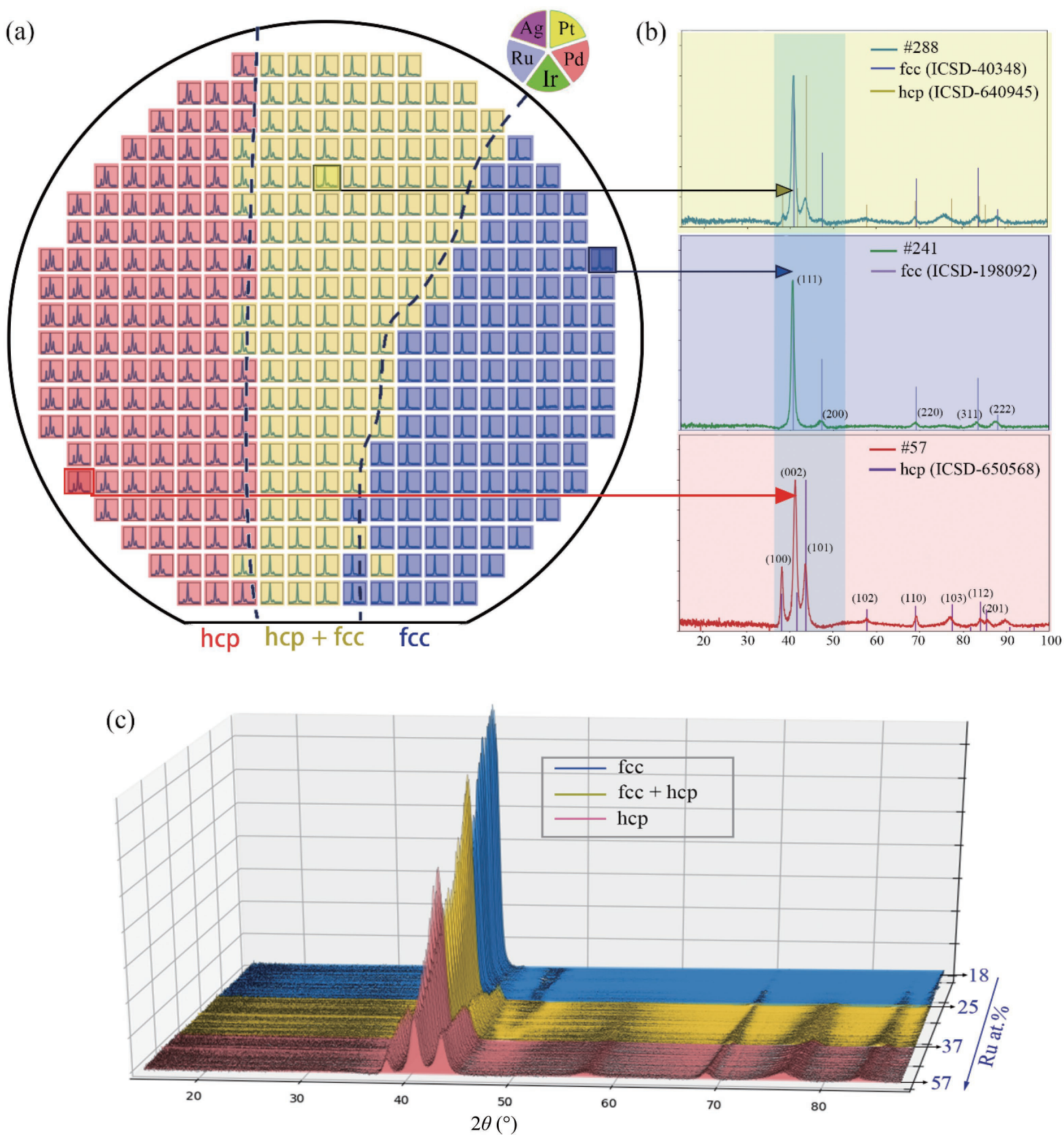

Figure 3 Phase and XRD map of the as-deposited Ag-Ir-Pd-Pt-Ru ML. This ML is crystalline and composed of either pure hcp or pure fcc or mixed hcp + fcc phase. The legend indicates the respective element positions during deposition. (a) Based on the observed $342 \mathrm{XRD}$ patterns, the ML is separated into three phase regions by two dashed lines. (b) Magnified views of three typical MAs show mixed fcc and hcp (yellow), pure fcc (blue) and pure hcp (red) phases, respectively. (c) Waterfall plot shows the peak shift and splitting along the Ru composition gradient.

Table 2 Crystal structure, lattice parameter $(a, c)$, atomic radius $(r)$, and melting temperature ( $\left.T_{\mathrm{m}}\right)$, for $\mathrm{Ag}$ [53], Ir [54], Pd [55], Pt [56] and Ru [57]

\begin{tabular}{cccccc}
\hline & $\mathrm{Ag}$ & $\mathrm{Ir}$ & $\mathrm{Pd}$ & $\mathrm{Pt}$ & $\mathrm{Ru}$ \\
\hline Structure & $\mathrm{fcc}$ & $\mathrm{fcc}$ & $\mathrm{fcc}$ & $\mathrm{fcc}$ & $\mathrm{hcp}$ \\
$a(\mathrm{~nm})$ & 0.409 & 0.384 & 0.389 & 0.392 & 0.271 \\
$c(\mathrm{~nm})$ & 0.409 & 0.384 & 0.389 & 0.392 & 0.428 \\
$r(\mathrm{~nm})$ & 0.137 & 0.135 & 0.134 & 0.135 & 0.134 \\
$T_{\mathrm{m}}\left({ }^{\circ} \mathrm{C}\right)$ & 962 & 2,466 & 1,555 & 1,768 & 2,334 \\
\hline
\end{tabular}

of Ag-Ir-Pd-Pt-Ru was examined. Figure 5 summarizes the phase evolution in Ag-Ir-Pd-Pt-Ru ML in dependence of temperature (as-deposited, annealing temperatures of 600, 700, 800, and $900{ }^{\circ} \mathrm{C}$, each for $10 \mathrm{~h}$ ). The corresponding phase constitutions (proportions of fcc, fcc + hcp or hcp) after annealing are listed in Table 3. Several trends in the phase evolution with increasing
$T_{\text {anneal }}$ are found. In the case of pure hcp region, its fraction first rises and then falls, with the highest value of $51 \%$ occurring at $T_{\text {anneal }}=$ $600{ }^{\circ} \mathrm{C}$. On the other hand, the portion of mixed hcp + fcc phases grows steadily from the as-deposited $37 \%$ to $76 \%$ at $T_{\text {anneal }}=700$ ${ }^{\circ} \mathrm{C}$, and reaches $100 \%$ at $T_{\text {anneal }}=900{ }^{\circ} \mathrm{C}$. This means increased temperature allows the co-existence of both hcp and fcc phases over a broader compositional range. The purely fcc region demonstrates a totally different tendency upon annealing, as even after the lowest annealing temperature of $600{ }^{\circ} \mathrm{C}$ it co-exists with hcp phase.

These results show that the phase constitution of the films is dependent on $T_{\text {anneal- }}$. First, before $T_{\text {anneal }}$ reaches $600{ }^{\circ} \mathrm{C}$, the purely fcc phase region on the right side of $\mathrm{ML}$ becomes mixed with some hcp phase. Large parts of the mixed phase located in the middle ML also transform into hcp. Second, the noble metal MPEAs become unstable and start to gradually decompose when 

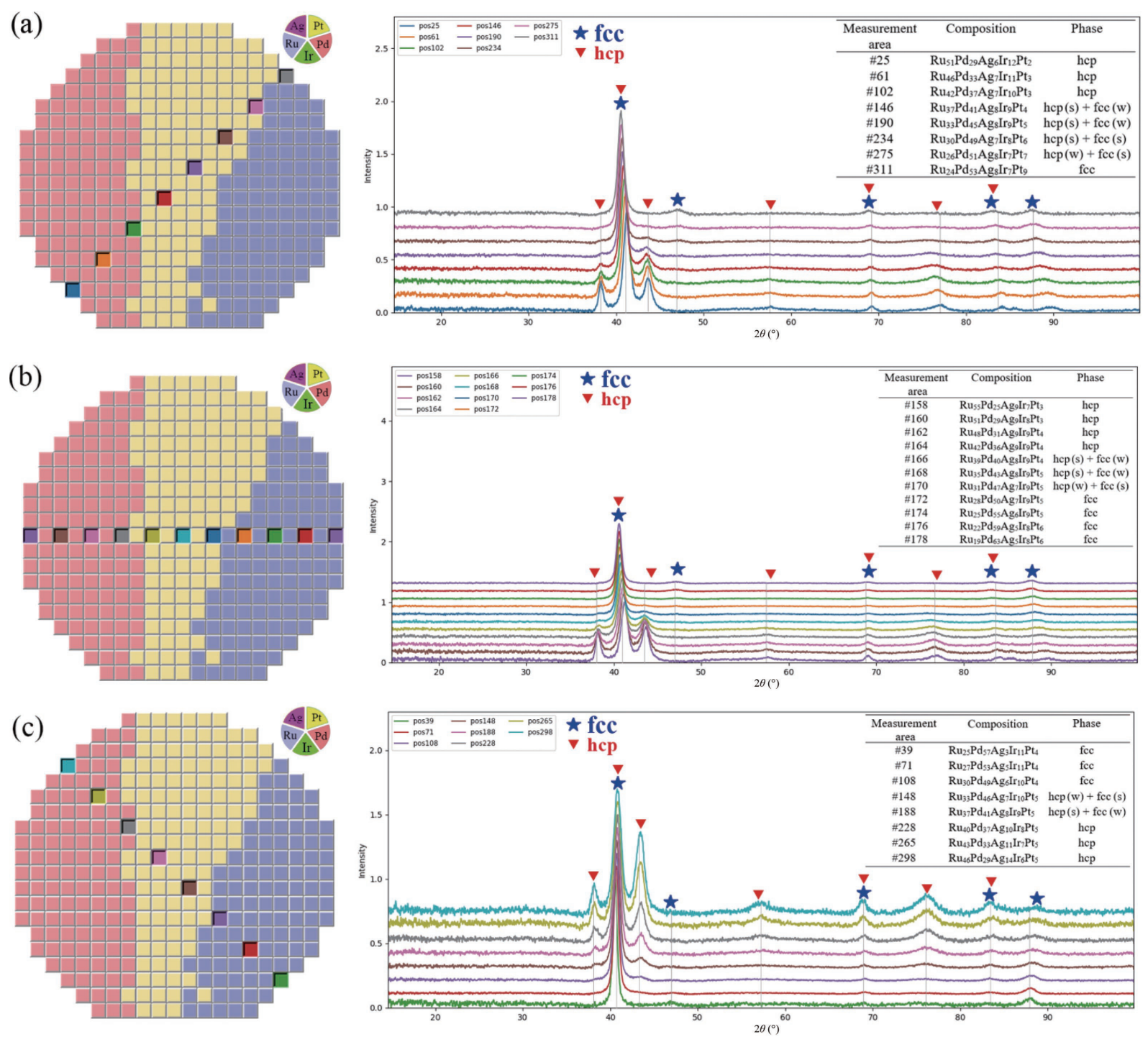

Figure 4 Visualization of correlation between constituent compositions and phases for a series of selected MAs in the as-deposited ML: (a) from bottom left (Ru-rich) to top right (Pd-rich), (b) from left (Ru-rich) to right (Pd-rich), (c) from top left (Ag-rich) to bottom right (Ag-poor). These MAs are chosen such that they capture the representative characteristics of the phase evolution in sufficient composition ranges. Insets of (a)-(c): w and s stand for minor (weak) and major (strong) phases, respectively.

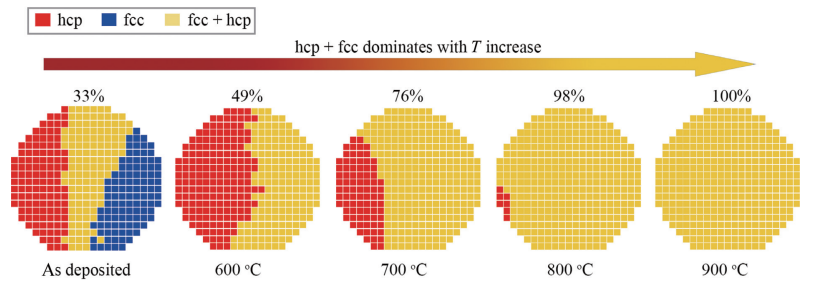

Figure 5 Phase maps in the as-deposited state and after annealing at increasing temperatures. The number of MAs composed of mixed hcp and fcc phases increases steadily from $33 \%$ to $100 \%$ with increasing annealing temperature. This growth of the mixture phase is accompanied by a partial fcc-hcp phase transition (below $600{ }^{\circ} \mathrm{C}$ ) and the MPEAs decomposition (above $600{ }^{\circ} \mathrm{C}$ ). The decomposition products are composed of elemental Ir (fcc), Pd (fcc), $\mathrm{Pt}(\mathrm{fcc})$ and $\mathrm{Ru}(\mathrm{hcp})$. EDX results indicate a deficiency of $\mathrm{Ag}$ (around $10 \%$ loss compared to as-deposited state) after annealing at $900^{\circ} \mathrm{C}$.

$T_{\text {anneal }}>600{ }^{\circ} \mathrm{C}$. The resulting decomposition products include metals such as Ag, Pd, Ir, Pt or Ru, as confirmed by XPS analysis. The sample used for XPS analysis has a composition of $\mathrm{Ag}_{10} \mathrm{Pt}_{20} \mathrm{Ir}_{8} \mathrm{Ru}_{31} \mathrm{Pd}_{31}$. Results are shown in the ESM. Compositions (see Table S1 in the ESM) are obtained by averaging the analysis of 5-7 data points obtained at a given temperature state. Significant $\mathrm{Ag}$ and $\mathrm{Pd}$ deficiencies are detected after $T_{\text {anneal }}=900{ }^{\circ} \mathrm{C}$ with
Table 3 Phase constitution (proportions of fcc, fcc + hcp and hcp) of ML after annealing at different temperatures

\begin{tabular}{cccccc}
\hline & As deposited & $600{ }^{\circ} \mathrm{C}$ & $700{ }^{\circ} \mathrm{C}$ & $800{ }^{\circ} \mathrm{C}$ & $900{ }^{\circ} \mathrm{C}$ \\
\hline hcp & $33 \%$ & $51 \%$ & $24 \%$ & $2 \%$ & 0 \\
hcp + fcc & $37 \%$ & $49 \%$ & $76 \%$ & $98 \%$ & $100 \%$ \\
fcc & $30 \%$ & 0 & 0 & 0 & 0 \\
\hline
\end{tabular}

respect to the as-deposited composition. Moreover, the binding energy of each element shifts differently as temperature increases. The peaks related to energy levels $\mathrm{Ag} 3 \mathrm{~d} 5$, Pt 4f7, Ir $4 \mathrm{f} 5$ and Pd $3 \mathrm{~d} 3$ shift to higher binding energies $(+0.1,+0.3,+0.1$, and +0.3 $\mathrm{eV})$, while $\mathrm{Ru} 3 \mathrm{~d} 5$ moves to lower energies $(-0.2 \mathrm{eV})$. The composition changes and binding energy shifts indicate that the sample decomposes into its subsystem solid solutions.

Furthermore, EDX analysis shows a significant Ag-deficiency (more than $10 \%$ loss) after $T_{\text {anneal }}=900{ }^{\circ} \mathrm{C}$ with respect to the asdeposited composition, consistent with the XPS data shown in Table S1 in the ESM. Moreover, as mentioned above, among all the five elemental phases (Ag, Ir, Pd, Pt and $\mathrm{Ru}$ ), only $\mathrm{Ru}$ crystallizes in hcp, whereas the other elements are fcc. By combining EDX and XPS experimental results, we conclude that 
the films become unstable over $600{ }^{\circ} \mathrm{C}$ and start to decompose into the elementary components of $\mathrm{Ir}(\mathrm{fcc}), \mathrm{Pd},(\mathrm{fcc}) \mathrm{Pt}(\mathrm{fcc})$ and $\mathrm{Ru}(\mathrm{hcp})$. This is the reason why the $\mathrm{fcc}+\mathrm{hcp}$ phases region has become prominent with an increase in $T_{\text {anneal }}$.

In order to substantiate the influence of temperature on phase transitions, MA \#278 with composition of $\mathrm{Ag}_{5} \mathrm{Ir}_{8} \mathrm{Pd}_{56} \mathrm{Pt}_{8} \mathrm{Ru}_{23}$ was selected as a representative for temperature-dependent XRD measurement performed in a vacuum dome (Bruker). This composition was selected because its initial fcc structure in the asdeposited state will transform into hcp upon heating. The sample was heated from 25 to $600{ }^{\circ} \mathrm{C}$ with a heating rate of $4{ }^{\circ} \mathrm{C} / \mathrm{min}$. $\mathrm{XRD}$ patterns were continually collected during heating, with exposure time of $30 \mathrm{~s}$. $\mathrm{XRD}(\mathrm{T})$ was restricted to temperatures $\leq$ $600{ }^{\circ} \mathrm{C}$ as the $\mathrm{X}$-ray transparent dome that provides a protective environment for samples can reach only a low vacuum $(1.3 \mathrm{~Pa})$, which is not enough to prevent oxidation and decomposition at higher temperatures.

Figure 6(b) displays the XRD results for this MA at different temperatures (room temperature, and annealed at 500, 700, and $900{ }^{\circ} \mathrm{C}$ ). At room temperature, $\mathrm{Ag}_{5} \mathrm{Ir}_{8} \mathrm{Pd}_{56} \mathrm{Pt}_{8} \mathrm{Ru}_{23}$ forms an fcc phase with lattice parameter $a=0.3846 \mathrm{~nm}$. When this MA is annealed, two characteristic behaviors can be observed. First, for $T_{\text {anneal }}=500{ }^{\circ} \mathrm{C}$, an additional weak peak is identified at a $2 \theta$ angle of $35^{\circ}$. This weak diffraction peak is characteristic for the ordered C14 type Laves phase, which possesses a hcp structure (space group $P 6_{3} / m m c$ ) [43-45]. Laves phases are size compounds and their formation and stability primarily depends on parameters such as atomic radii ratio, electronegativity difference and valence electron concentration [46-47]. Here, the transition to hexagonal Laves phase from the fcc phase could be attributed to the slight crystal lattice distortion induced by high temperature, and its appearance marks the beginning of an fcc-hcp phase transition. Second, when $T_{\text {anneal }}$ increases to $700^{\circ} \mathrm{C}$, the peak characteristic for Laves phase is no longer observed. However, typical hcp peaks such as (100) at $2 \theta=38^{\circ}$ and (101) at $2 \theta=44^{\circ}$ appear. As mentioned before, the observation that both fcc and hcp phases still coexist after being annealed at $900{ }^{\circ} \mathrm{C}$ is due to the formation of metallic phases (Ir, Pd, Pt and $\mathrm{Ru}$ ) resulting from the MPEA's decomposition.

The position and intensity of the Laves phase peak are well comparable with that reported for fcc-CoCrFeNb${ }_{x} \mathrm{Ni}(0.25<x<$ 1.2), where the Laves phase becomes dominant with increasing $\mathrm{Nb}$ content [48]. In fact, Laves phase is commonly observed in many MPEAs as a minor phase that precipitates inside the main phase when additional elements such as $\mathrm{Nb}$ or $\mathrm{Ti}$ are added [5]. For instance, a (CoCr)Nb-type Laves phase mixed with fcc phase is reported for $\mathrm{CoCrCuFeNiNb}$, whereas this alloy shows a singlephase fcc structure when $\mathrm{Nb}$ is absent [49]. Another example is $\mathrm{Al}_{0.5} \mathrm{CoCrFeNiTi}$, where a $\mathrm{Fe}_{2}$ Ti-type Laves phase occurs at high Ti content $(x=1.5)$, while only a single-phase solid solution is
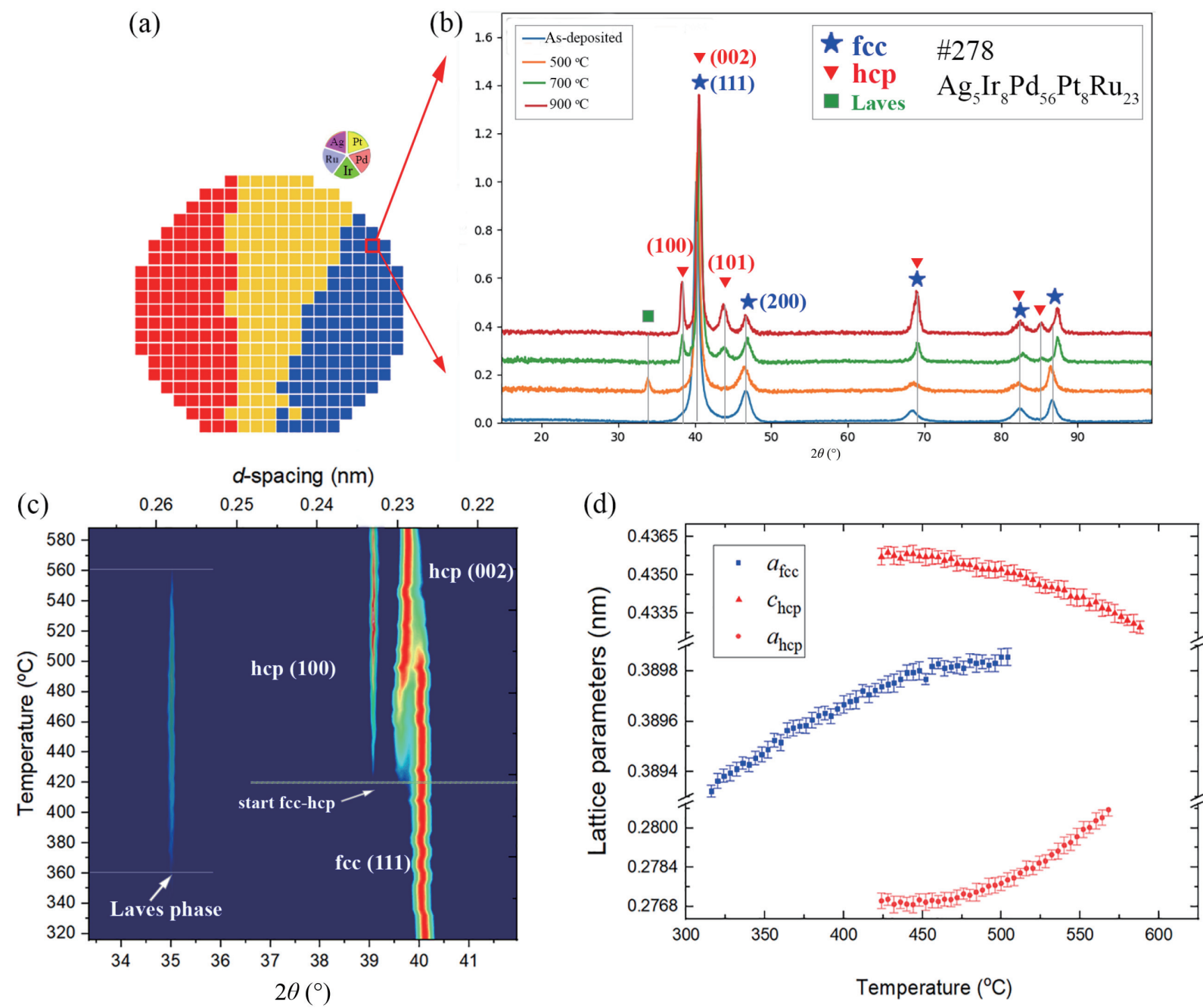

Figure 6 Temperature-dependent phase transition of $\mathrm{Ag}_{5} \mathrm{Ir}_{8} \mathrm{Pd}_{56} \mathrm{Pt}_{8} \mathrm{Ru}_{23}$ (MA \#278). (a) The location of selected MA in the ML. Note that it has fcc phase at room temperature. (b) Comparison of as-deposited XRD patterns with those after different annealing temperatures $\left(500,700\right.$, and $\left.900{ }^{\circ} \mathrm{C}\right)$. (c) XRD contour plot showing the fcc-hcp phase transition. The fcc (111) peak and the hexagonal (100)/(002) peaks are shown as a function of temperature. There is a wide range of cubic and tetragonal phase coexistence from 420 to $510^{\circ} \mathrm{C}$. (d) Variations of lattice parameters of fcc and hcp phases. The lattice parameters are determined from the XRD scans of the cubic (111) and hexagonal (100)/(002) Bragg reflections. 
present up to $x=1$ [50]. Based on our annealing experiment, we conclude that the C14 Laves phase plays an important role in initiating and assisting the phase transition from fcc to hcp, because this phase bears the similar hexagonal close-packed structure with that of hcp and it exists only in a part of the heating process and disappears when the hcp phase forms.

Temperature-dependent XRD patterns were collected from 25 and $600{ }^{\circ} \mathrm{C}$ to characterize the phase transition details. The contour plot covering the phase transition region is shown in Fig. 6(c). The transformation details between the cubic and hexagonal phases can be clearly seen. At a low angle, the peak of the Laves phase located at around $2 \theta=35^{\circ}$ is found for temperatures from 360 to $560{ }^{\circ} \mathrm{C}$. The advent of Laves phase suggests the formation of an ordered structure with a hexagonal unit cell. The transient appearance of the Laves phase is consistent with the prior multi-step annealing experiment. At a higher angle of $2 \theta=40.3^{\circ}$, a well-defined, high-intensity peak corresponding to the (111) reflection of an fcc phase can be seen. As the temperature increases, this peak slowly shifts to a lower $2 \theta$ angle and it finally disappears when the temperature reaches $510^{\circ} \mathrm{C}$. This is due to a shift in the cell parameters caused by thermal expansion. Such an effect is quantified by Bragg's law, and the result is shown below. In the middle range, two well-resolved peaks which are located at around $2 \theta=38.3^{\circ}$ and $2 \theta=40.0^{\circ}$, respectively, appear at temperatures above $420{ }^{\circ} \mathrm{C}$. Both are characteristic peaks that belong to (100) and (111) reflections of an hcp phase, and their appearance marks the beginning of the fcc-hcp phase transition.

The peak positions extracted from the XRD data allow calculation of the $d$-spacing from Bragg's law $2 d \sin \theta=n \lambda$, where $\theta$ is the diffraction angle, $\lambda$ is the wavelength, and $n$ is the diffraction order. The peak positions are obtained by fitting a Gaussian function to each XRD pattern at each temperature. In the case of the hcp phase, the out-of-plane and in-plane lattice constants $c$, and $a$ of the hexagonal unit cell can be calculated using Vegard's law [51-52]. The refined lattice parameters for both fcc and hcp structures as a function of temperature are given in Fig. 6(d).

\section{Conclusion}

A quinary noble metal Ag-Ir-Pd-Pt-Ru ML containing 342 MAs of gradually different compositions was fabricated by combinatorial co-deposition and characterized by highthroughput methods. The ML has a center composition of $\mathrm{Ag}_{10} \mathrm{Ir}_{9} \mathrm{Pd}_{41} \mathrm{Pt}_{5} \mathrm{Ru}_{35}$ and covers a broad compositional space of $\mathrm{Ag}_{2-14} \mathrm{Ir}_{6-14} \mathrm{Pd}_{25-64} \mathrm{Pt}_{2-10} \mathrm{Ru}_{18-57}$. The phase map for this ML shows three regions: hcp, hcp + fcc, and fcc. The compositional studies of the ML indicate that the observed phase constitution could be quantitatively explained by the $\mathrm{Ru}$ content. Lower $\mathrm{Ru}$ contents between 18 at.\% and 25 at.\% promote fcc solid-solution phases, while high $\mathrm{Ru}$ contents between 37 at.\% and 57 at.\% favor the formation of hcp solid-solution phases.

Temperature-dependent phase constitution behavior is observed by annealing experiments. At increased temperatures the co-existence of a mixture of phases over a broader composition range is possible. For temperatures over $600{ }^{\circ} \mathrm{C}$, the films become unstable and decompose into their subsystem solid solutions. All temperature-induced phase transitions in this study are irreversible, because these transitions are observed only by the heating process and cannot be seen in the cooling process. The temperature-dependent XRD results for $\mathrm{Ag}_{6} \mathrm{Ir}_{8} \mathrm{Pd}_{56} \mathrm{Pt}_{8} \mathrm{Ru}_{23}$ show that its phase changes from initially fcc to an intermediate C14type Laves phase at $360{ }^{\circ} \mathrm{C}$, and finally to hcp when the temperature reaches $510^{\circ} \mathrm{C}$. The formation and disappearance of a hexagonal Laves phase, which covers a wide temperature range, are a crucial role for bridging the fcc-hcp phase transition. Our observations provide insights into the nature of the compositionaland temperature-dependent phase evolution in this portion of the Ag-Ir-Pd-Pt-Ru system. The phase constitution can be engineered by adjusting the relative fractions of fcc and hcp through tuning composition and heat treatment which can be used to optimize mixed-phase alloys with tunable functional properties.

\section{Acknowledgements}

ZGH is acknowledged for the use of its scientific infrastructure. This work was funded by Deutsche Forschungsgemeinschaft (DFG), projects LU1175/26-1 and LU1175/22-1.

Funding note: Open Access funding enabled and organized by Projekt DEAL.

Electronic Supplementary Material: Supplementary material (thickness mapping data and XPS results of Ag-Ir-Pd-Pt-Ru ML) is available in the online version of this article at https:// doi.org/10.1007/s12274-021-3516-7.

Open Access This article is licensed under a Creative Commons Attribution 4.0 International License, which permits use, sharing, adaptation, distribution and reproduction in any medium or format, as long as you give appropriate credit to the original author(s) and the source, provide a link to the Creative Commons licence, and indicate if changes were made.

The images or other third party material in this article are included in the article's Creative Commons licence, unless indicated otherwise in a credit line to the material. If material is not included in the article's Creative Commons licence and your intended use is not permitted by statutory regulation or exceeds the permitted use, you will need to obtain permission directly from the copyright holder.

To view a copy of this licence, visit http://creativecommons. org/licenses/by/4.0/.

\section{References}

[1] Yeh, J. W.; Chen, S. K.; Lin, S. J.; Gan, J. Y.; Chin, T. S.; Shun, T. T.; Tsau, C. H.; Chang, S. Y. Nanostructured high-entropy alloys with multiple principal elements: Novel alloy design concepts and outcomes. Adv. Eng. Mater. 2004, 6, 299-303.

[2] Zhang, Y.; Zuo, T. T.; Tang, Z.; Gao, M. C.; Dahmen, K. A.; Liaw, P. K.; Lu, Z. P. Microstructures and properties of high-entropy alloys. Prog. Mater. Sci. 2014, 61, 1-93.

[3] Tsai, M. H.; Yeh, J. W. High-entropy alloys: A critical review. Mater. Res. Lett. 2014, 2, 107-123.

[4] Tsai, K. Y.; Tsai, M. H.; Yeh, J. W. Sluggish diffusion in Co-Cr-Fe-Mn-Ni high-entropy alloys. Acta Mater. 2013, 61, 4887-4897.

[5] Murty, B. S.; Yeh, J. W.; Ranganathan, S.; Bhattacharjee, P. HighEntropy Alloys. Elsevier, 2019.

[6] George, E. P.; Raabe, D.; Ritchie, R. O. High-entropy alloys. Nat. Rev. Mater. 2019, 4, 515-534.

[7] Yeh, J. W. Recent progress in high-entropy alloys. Eur. J. Control. 2006, 31, 633-648.

[8] Senkov, O. N.; Wilks, G. B.; Miracle, D. B.; Chuang, C. P.; Liaw, P. K. Refractory high-entropy alloys. Intermetallics 2010, 18, $1758-1765$.

[9] Hsu, Y. J.; Chiang, W. C.; Wu, J. K. Corrosion behavior of $\mathrm{FeCoNiCrCu}$ high-entropy alloys in $3.5 \%$ sodium chloride solution. Mater. Chem. Phys. 2005, 92, 112-117.

[10] Kao, Y. F.; Chen, T. J.; Chen, S. K.; Yeh, J. W. Microstructure and mechanical property of as-cast, -homogenized, and -deformed 
$\mathrm{Al}_{x} \mathrm{CoCrFeNi}(0 \leq x \leq 2)$ high-entropy alloys. J. Alloys Compd. 2009, 488, 57-64.

[11] Li, Z. Z.; Zhao, S. T.; Ritchie, R. O.; Meyers, M. A. Mechanical properties of high-entropy alloys with emphasis on face-centered cubic alloys. Prog. Mater. Sci. 2019, 102, 296-345.

[12] Steurer, W. Single-phase high-entropy alloys-A critical update. Mater. Charact. 2020, 162, 110179.

[13] Senkov, O. N.; Wilks, G. B.; Scott, J. M.; Miracle, D. B. Mechanical properties of $\mathrm{Nb}_{25} \mathrm{Mo}_{25} \mathrm{Ta}_{25} \mathrm{~W}_{25}$ and $\mathrm{V}_{20} \mathrm{Nb}_{20} \mathrm{Mo}_{20} \mathrm{Ta}_{20} \mathrm{~W}_{20}$ refractory high entropy alloys. Intermetallics 2011, 19, 698-706.

[14] Senkov, O. N.; Scott, J. M.; Senkova, S. V.; Miracle, D. B.; Woodward, C. F. Microstructure and room temperature properties of a high-entropy TaNbHfZrTi alloy. J. Alloys Compd. 2011, 509, 6043-6048.

[15] Singh, P.; Smirnov, A. V.; Johnson, D. D. Ta-Nb-Mo-W refractory high-entropy alloys: Anomalous ordering behavior and its intriguing electronic origin. Phys. Rev. Mater. 2018, 2, 055004.

[16] Youssef, K. M.; Zaddach, A. J.; Niu, C. N.; Irving, D. L.; Koch, C. C. A novel low-density, high-hardness, high-entropy alloy with closepacked single-phase nanocrystalline structures. Mater. Res. Lett. 2015, 3, 95-99.

[17] Lužnik, J.; Koželj, P.; Vrtnik, S.; Jelen, A.; Jagličić, Z.; Meden, A.; Feuerbacher, M.; Dolinšek, J. Complex magnetism of Ho-Dy-Y-GdTb hexagonal high-entropy alloy. Phys. Rev. B 2015, 92, 224201.

[18] Soler, R.; Evirgen, A.; Yao, M.; Kirchlechner, C.; Stein, F.; Feuerbacher, M.; Raabe, D.; Dehm, G. Microstructural and mechanical characterization of an equiatomic YGdTbDyHo high entropy alloy with hexagonal close-packed structure. Acta Mater. 2018, 156, 86-96

[19] Pedersen, J. K.; Batchelor, T. A. A.; Bagger, A.; Rossmeisl, J. Highentropy alloys as catalysts for the $\mathrm{CO}_{2}$ and $\mathrm{CO}$ reduction reactions. ACS Catal. 2020, 10, 2169-2176.

[20] Sohn, S.; Liu, Y. H.; Liu, J. B.; Gong, P.; Prades-Rodel, S.; Blatter, A.; Scanley, B. E.; Broadbridge, C. C.; Schroers, J. Noble metal high entropy alloys. Scr. Mater. 2017, 126, 29-32.

[21] Yin, B. L.; Curtin, W. A. First-principles-based prediction of yield strength in the RhIrPdPtNiCu high-entropy alloy. npj Comput. Mater. 2019, 5, 14.

[22] Yusenko, K. V.; Riva, S.; Carvalho, P. A.; Yusenko, M. V.; Arnaboldi, S.; Sukhikh, A. S.; Hanfland, M.; Gromilov, S. A. First hexagonal close packed high-entropy alloy with outstanding stability under extreme conditions and electrocatalytic activity for methanol oxidation. Scr. Mater. 2017, 138, 22-27.

[23] Nellaiappan, S.; Katiyar, N. K.; Kumar, R.; Parui, A.; Malviya, K. D.; Pradeep, K. G.; Singh, A. K.; Sharma, S.; Tiwary, C. S.; Biswas, $\mathrm{K}$. High-entropy alloys as catalysts for the $\mathrm{CO}_{2}$ and $\mathrm{CO}$ reduction reactions: Experimental realization. ACS Catal. 2020, 10, $3658-3663$.

[24] d'Acremont, Q.; Pernot, G.; Rampnoux, J. M.; Furlan, A.; Lacroix, D.; Ludwig, A.; Dilhaire, S. High-throughput heterodyne thermoreflectance: Application to thermal conductivity measurements of a Fe-Si-Ge thin film alloy library. Rev. Sci. Instrum. 2017, 88, 074902.

[25] Khare, C.; Sliozberg, K.; Stepanovich, A.; Schuhmann, W.; Ludwig, A. Combinatorial synthesis and high-throughput characterization of structural and photoelectrochemical properties of $\mathrm{Fe}: \mathrm{WO}_{3}$ nanostructured libraries. Nanotechnology 2017, 28, 185604.

[26] Li, Z. M.; Ludwig, A.; Savan, A.; Springer, H.; Raabe, D. Combinatorial metallurgical synthesis and processing of highentropy alloys. J. Mater. Res. 2018, 33, 3156-3169.

[27] Lowry, M. S.; Hudson, W. R.; Pascal, R. A.; Bernhard, S. Accelerated luminophore discovery through combinatorial synthesis. J. Am. Chem. Soc. 2004, 126, 14129-14135.

[28] Briceño, G.; Chang, H.; Sun, X. D.; Schultz, P. G.; Xiang, X. D. A class of cobalt oxide magnetoresistance materials discovered with combinatorial synthesis. Science 1995, 270, 273-275.

[29] Wambach, M.; Nguyen, N.; Hamann, S.; Nishio, M.; Yagyu, S.; Chikyow, T.; Ludwig, A. Electrical and structural properties of the partial ternary thin-film system Ni-Si-B. ACS Comb. Sci. 2019, 21, $310-315$.

[30] Wang, X.; Rogalla, D.; Ludwig, A. Influences of W content on the phase transformation properties and the associated stress change in thin film substrate combinations studied by fabrication and characterization of thin film $\mathrm{V}_{1-x} \mathrm{~W}_{x} \mathrm{O}_{2}$ materials libraries. $A C S$ Comb. Sci. 2018, 20, 229-236.

[31] Hanak, J. J. The "multiple-sample concept" in materials research: Synthesis, compositional analysis and testing of entire multicomponent systems. J. Mater. Sci. 1970, 5, 964-971.

[32] Hanak, J. J.; Gittleman, J. I.; Pellicane, J. P.; Bozowski, S. The effect of grain size on the superconducting transition temperature of the transition metals. Phys. Lett. A 1969, 30, 201-202.

[33] Böttcher, A.; Haase, G.; Thun, R. Strukturuntersuchung von Mehrstoffsystemen durch kinematische Elektronenbeugung. $Z$. Metallkde. 1955, 46, 386-400.

[34] Schweizer, F.; Hindsgaul, O. Combinatorial synthesis of carbohydrates. Curr. Opin. Chem. Biol. 1999, 3, 291-298.

[35] Li, Y. J.; Kostka, A.; Savan, A.; Ludwig, A. Atomic-scale investigation of fast oxidation kinetics of nanocrystalline CrMnFeCoNi thin films. J. Alloys Compd. 2018, 766, 1080-1085.

[36] Ludwig, A. Discovery of new materials using combinatorial synthesis and high-throughput characterization of thin-film materials libraries combined with computational methods. npj Comput. Mater. 2019, 5,70 .

[37] Naujoks, D.; Weiser, M.; Salomon, S.; Stein, H.; Virtanen, S.; Ludwig, A. Combinatorial study on phase formation and oxidation in the thin film superalloy subsystems $\mathrm{Co}-\mathrm{Al}-\mathrm{Cr}$ and $\mathrm{Co}-\mathrm{Al}-\mathrm{Cr}-\mathrm{W}$. ACS Comb. Sci. 2018, 20, 611-620.

[38] Kumari, S.; Gutkowski, R.; Junqueira, J. R. C.; Kostka, A.; Hengge, K.; Scheu, C.; Schuhmann, W.; Ludwig, A. Combinatorial synthesis and high-throughput characterization of Fe- $\mathrm{V}-\mathrm{O}$ thin-film materials libraries for solar water splitting. ACS Comb. Sci. 2018, 20, 544-553.

[39] Batchelor, T. A. A.; Löffler, T.; Xiao, B.; Krysiak, O. A.; Strotkötter, V.; Pedersen, J. K.; Clausen, C. M.; Savan, A.; Li, Y. J.; Schuhmann, W. Complex-solid-solution electrocatalyst discovery by computational prediction and high-throughput experimentation. Angew. Chem., Int. Ed. 2020, 133, 7008-7013.

[40] Liu, X. H.; Luo, J.; Zhu, J. Size effect on the crystal structure of silver nanowires. Nano Lett. 2006, 6, 408-412.

[41] Guo, Q. X.; Zhao, Y. S.; Mao, W. L.; Wang, Z. W.; Xiong, Y. J.; Xia, Y. N. Cubic to tetragonal phase transformation in coldcompressed Pd nanocubes. Nano Lett. 2008, 8, 972-975.

[42] Zhang, Q.; Kusada, K.; Wu, D. S.; Yamamoto, T.; Toriyama, T.; Matsumura, S.; Kawaguchi, S.; Kubota, Y.; Kitagawa, H. Selective control of fcc and hep crystal structures in $\mathrm{Au}-\mathrm{Ru}$ solid-solution alloy nanoparticles. Nat. Commun. 2018, 9, 510

[43] Rabadia, C. D.; Liu, Y. J.; Wang, L.; Sun, H.; Zhang, L. C. Laves phase precipitation in $\mathrm{Ti}-\mathrm{Zr}-\mathrm{Fe}-\mathrm{Cr}$ alloys with high strength and large plasticity. Mater. Des. 2018, 154, 228-238.

[44] Erdmann, B.; Keller, C. Actinide(lanthanide)-noble metal alloy phases, preparation and properties. J. Solid State Chem. 1973, 7, 40-48.

[45] Compton, V. B.; Matthias, B. T. Laves phase compounds of rare earths and hafnium with noble metals. Acta Cryst. 1959, 12, 651-654.

[46] Stein, F.; Palm, M.; Sauthoff, G. Structure and stability of Laves phases. Part I. Critical assessment of factors controlling Laves phase stability. Intermetallics 2004, 12, 713-720.

[47] Scudino, S.; Donnadieu, P.; Surreddi, K. B.; Nikolowski, K.; Stoica, M.; Eckert, J. Microstructure and mechanical properties of Laves phase-reinforced $\mathrm{Fe}-\mathrm{Zr}-\mathrm{Cr}$ alloys. Intermetallics 2009, 17, 532-539.

[48] Jiang, H.; Jiang, L.; Qiao, D. X.; Lu, Y. P.; Wang, T. M.; Cao, Z. Q.; $\mathrm{Li}, \mathrm{T}$. J. Effect of niobium on microstructure and properties of the $\mathrm{CoCrFeNb}_{x} \mathrm{Ni}$ high entropy alloys. J. Mater. Sci. Technol. 2017, 33, 712-717.

[49] Cheng, J. B.; Liang, X. B.; Xu, B. S. Effect of Nb addition on the structure and mechanical behaviors of $\mathrm{CoCrCuFeNi}$ high-entropy alloy coatings. Surf. Coat. Technol. 2014, 240, 184-190.

[50] Zhou, Y. J.; Zhang, Y.; Wang, Y. L.; Chen, G. L. Solid solution alloys of $\mathrm{Al} \mathrm{Co} \mathrm{Cr} F \mathrm{Ni} \mathrm{Ti}_{x}$ with excellent room-temperature mechanical properties. Appl. Phys. Lett. 2007, 90, 181904.

[51] Zhou, D.; Usher, B. F. Deviation of the AlGaAs lattice constant from 
Vegard's law. J. Phys. D: Appl. Phys. 2001, 34, 1461.

[52] Li, W.; Pessa, M.; Likonen, J. Lattice parameter in GaNAs epilayers on GaAs: Deviation from Vegard's law. Appl. Phys. Lett. 2001, 78, 2864-2866.

[53] Liu, L. G.; Bassett, W. A. Compression of Ag and phase transformation of NaCl. J. Appl. Phys. 1973, 44, 1475-1479.

[54] Singh, H. P. Determination of thermal expansion of germanium, rhodium and iridium by X-rays. Acta Cryst 1968, A24, 469-471.

[55] Bredig, G.; Allolio, R. Röntgenuntersuchungen an katalytisch wirkenden Metallen. Z. Phys. Chem. 1927, 126, 41-71.

[56] Edwards, J. W.; Speiser, R.; Johnston, H. L. High temperature structure and thermal expansion of some metals as determined by $\mathrm{X}$ ray diffraction data. I. Platinum, tantalum, niobium, and molybdenum. J. Appl. Phys. 1951, 22, 424-428.

[57] Schroder, R. H.; Schmitz-Pranghe, N.; Kohlhaas, R. Experimentelle bestimmung der gitterparameter der platinmetalle im temperaturbereich -190 bis $1709^{\circ} \mathrm{C}$. Z. Metallkd. 1972, 63, 12-16. 